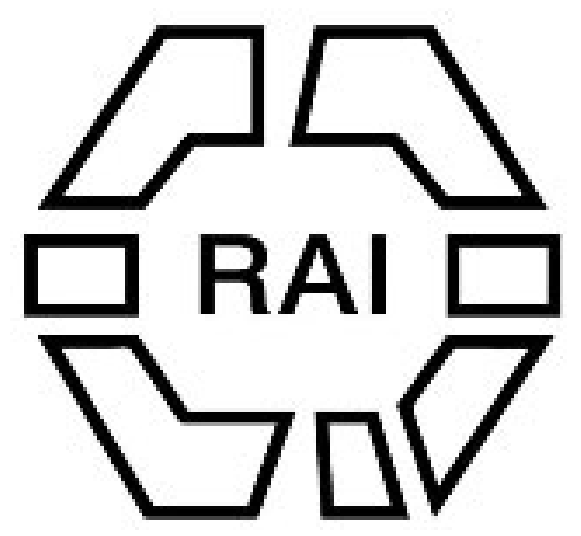

A Revised Nomenclature of the Inter-Oceanic Races of Men.

Author(s): S. J. Whitmee

Source: The Journal of the Anthropological Institute of Great Britain and Ireland, Vol. 8 (1879), pp. 360-369

Published by: Royal Anthropological Institute of Great Britain and Ireland

Stable URL: http://www.jstor.org/stable/2841078

Accessed: 14/06/2014 20:11

Your use of the JSTOR archive indicates your acceptance of the Terms \& Conditions of Use, available at http://www.jstor.org/page/info/about/policies/terms.jsp

JSTOR is a not-for-profit service that helps scholars, researchers, and students discover, use, and build upon a wide range of content in a trusted digital archive. We use information technology and tools to increase productivity and facilitate new forms of scholarship. For more information about JSTOR, please contact support@jstor.org.

Royal Anthropological Institute of Great Britain and Ireland is collaborating with JSTOR to digitize, preserve and extend access to The Journal of the Anthropological Institute of Great Britain and Ireland. 
The following paper was read by the author:-

\section{A Revised Nomenclature of the Inter-Oceanic Races of MEN.}

By Rev. S. J. Whitmee, F.R.G.S., C.M.Z.S.

THERE is much confusion in the use of Geographic and Ethnographic names in the Pacific. For example, the name Polynesia is used in different senses by different writers. Some employ it as a geographic term for all the intertropical islands eastward of New Guinea and Australia. Others employ it only for those islands which are eastward of Fiji ; and they use Melanesia and Micronesia for those islands which are south and north of the equator from Fiji westward. Those who use Polynesia in this restricted sense, employ it also as an ethnographic term for the brown race of men inhabiting that region. Others who give it the wider signification sometimes speak of the narrower region as "Polynesia Proper," and of the people living there as "true Polynesians." I have always employed Polynesia as a geographic term for all the intertropical islands eastward of Australia, New Guinea, and the Philippine Islands; while I have used Melanesia, Micronesia, and Malayo-Polynesia for the ethnographic divisions of that region.

While adopting these names, I have never been satisfied with them; but have tried to find some good distinctive terms which could be uniformly employed and which would commend themselves to the judgment of geographers and ethnologists generally. In the hope that I may contribute something towards a satisfactory settlement of this difficulty, I venture to present this paper to the Institute. I trust members and others interested in the subject who are present, will freely offer all the reasonable objections they can to my proposals, and suggest anything better which may occur to them. My wish is not to force my own proposals, if others better than mine can be found. I am anxious that we should have a good discussion which will result in fixing on such names as may be readily accepted by men of science generally both in Europe and America.

The present appears to be a good time for making a change in names, if one is to be made at all. The islands, people, and languages of the Pacific are now attracting a fair share of attention; some books are about to be published which will probably be standard works on the geography, ethnology, and philology of the Pacific throughout the civilised world, and these may fix the names used in them for all educated people. To mention only one work which will be shortly published in this country-there is Mr. Wallace's volume on Australasia 
and Polynesia in Mr. Stanford's Compendium of Geography and Travel. It is of the highest importance that in that book corrected names should be used, and not the old unsatisfactory ones we now have. And I am happy to know that the nomenclature we fix on here to-night will in all probability be adopted in the ethnographical portion of that volume.* Indeed, it is mainly owing to Mr. A. H. Keane, B.A., who is preparing the ethnological appendix to the book, that I have ventured to take up this question to-night. He suggested to me the principle which has guided me in forming the new names I have to propose, and also proposed some of the details which I have adopted.

Before entering on the ethnographical portion of my subject, I have one suggestion with regard to geographical names to make, viz.: that Polynesia should be the one and only name used for all the intertropical islands of the Pacific, eastward of the Philippines, New Guinea, and Australia; and that Micronesia and Melanesia, as geographical terms at any rate, be no longer used. Micronesia does not include anything like all the small islets in the Pacific. There are more than eighty atolls in the Tuamotu archipelago alone; and there are others elsewhere which certainly ought to come under Micronesia if such a term be used at all. And Melanesia as now used is not conterminous with the race of men for whose sake it was manufactured. If Polynesia be adopted as the one geographical name for all the intertropical islands of the Pacific, it will be as easy to indicate wide districts by east and west, north-east and north-west, as it is thus to indicate the different parts of a continent.

Coming now to the ethnographical names, for the sake of completeness I include in this survey Australasia, the Indian Archipelago, Madagascar, and Formosa, as well as Polynesia. Adopting a suggestion of Mr. Keane's, I have called the people inhabiting this whole region the INTER-OcEANIC RACES. It is convenient to have a general term to use in speaking of these people as a whole; and perhaps this name will serve that convenience.

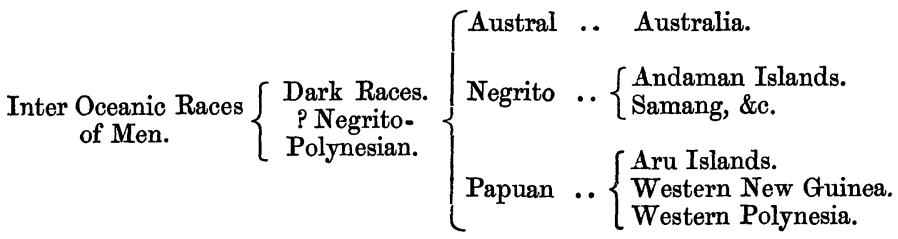

* The names suggested in this paper have not been used in Mr. Wallace's book. See his remarks in the discussion. 


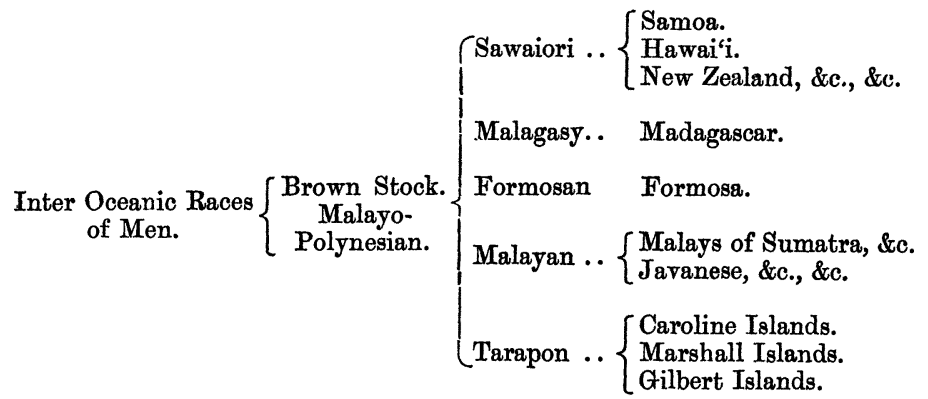

There are two broad and very distinct divisions of these people which appear on the surface : the Dark and the Brown races; the Dark occupying Australia, the Andaman Islands, portions of the Indian Archipelago, and Western Polynesia; the Brown being found in Madagascar, the Indian Archipelago, Formosa, North-Western and Eastern Polynesia, together with New Zealand.

It is an open question whether it is necessary or expedient to give one general name to the dark races. They differ very much, although in some broad characteristics they have affinity with one another. I am inclined to use a name to include the three races; although I am not prepared very strenuously to defend my preference. If we give them a general name, I would propose either Negrito-Polynesian, or Austro-Pacific Races. For the Brown people I propose the sole use in its widest signification of Baron William von Humboldt's name, Malayo-Polynesian. I would like to retain a name which has been already so widely used; but if there be strong objections to this, the term Indo-Pacific may serve for them. This latter uame would correspond with Indo-European and indicate the geographical distribution of the people.

I. The Dark, Negrito-Polynesian, or Austro-Pacific people, consist of three races. 1. The Australians, who may conveniently bear the name of the Austral Race. Some are inclined to put the extinct Tasmanians with the Australians; but it is extremely doubtful whether such a classification would be correct. The Tasmanians seem to have come nearer to the people of Western Polynesia than to the Australians. 2. The second race is that of which the Andaman Islanders may be regarded as the type. The Samangs of the Malacca peninsula, the Aetas and others of the Indian Archipelago belong to this race; and for them we already have a good name which cannot be bettered, viz. : Negrito. 3. The third race is found in Western New Guinea, the Aru Islands, and other places in the Indian Archipelago, and also in Western Polynesia. For these people 
there are now two names in use, and the question is, which shall we adopt? Papuan has been more or less applied to all of them, and it indicates one of their most striking and most constant characteristics, viz.: their frizzly hair. The other name, Melanesian, has been used for that part of the race found in Western Polynesia, but has never been applied to the whole race. I would prefer to see Papuan used for all. It appears certain that we ought to have only one name for all who have hitherto been called Papuans and Melanesians, and in choosing between the two I think the former is preferable to the latter.

Some people in the Indian Archipelago have been known as Alfuros or Alfurese. But I have always had a doubt whether these are a distinct race, and have not been inclined to assign them any distinct position. From recent information it is evident that Alfurc is used by the Mahomedans of the Indian Archipelago for pagans, whether they are brown or black people. They speak of "some Mahomedans, some Christians, and some Alfuros;" neither Mahomedan nor Christian, but pagan. This fact was brought under my notice by my friend Mr. Keane, and it seems to settle the question about using the name as an Ethnic appellation.

II. We come now to the Brown People, found over such a vast extent of Oceania. I hope we shall be able to retain William von Humboldt's name, Malayo-Polynesian, for this family; which, according to our present knowledge, I think may be classified under five sub-families or races.

In his useful synopsis of " the languages of the East Indies," Mr. Cust uses "Malayan" as a name for the family of languages spoken by all these brown people, with the exception of those in Polynesia. Mr Cust was confined by the geographical limits he set himself in that work, otherwise, of course, he would have included the languages of the brown Polynesians in that family. But I object to his name "Malayan" for the family, which encourages the idea that all the languages are derivatives from the Malay as at present spoken. That, however, I do not believe. I consider the Malay to be one of the most changed and developed languages of the whole family, occupying a position at the top of the tree instead of at its root.

Perhaps you will allow me for a minute to give you my idea of the affinities of these languages and peoples. I believe the parent stock of the whole family once occupied some part of the Indian Archipelago, or the Malacca Peninsula. The earliest migrating branch which separated itself from the parent stock, I believe was that whose descendants are now found in Eastern Polynesia and New Zealand. These people, occupying isolated positions, have retained, to a considerable extent, the language, 
customs, \&c., of the common stock. All the accretions they have gained have been from their contact here and there with the lower Papuan race, and possibly now and again from the arrival of a few people in a vessel driven from the Asiatic continent or islands. Any accretions thus gained would be very small indeed. But these people, in their small isolated communities, would doubtless lose some of the knowledge and civilisation which they originally possessed. There are evidences that they have deteriorated.* Hence I should say these Polynesians are somewhat lower now than the parent stock was when their ancestors separated from it, but are comparatively near to it.

At a date considerably later than the first Polynesian migration, another branch broke off from the main stock, and going westward, reached Madagascar. It remains for students of Malagasy to learn at what stage of Malay culture this migration took place. Probably the language will be the best instrument for determining this. From the presence of a few Sanscrit words in the Malagasy, I should think it took place after the Malay was affected by the Sanscrit.

I am unable to express any opinion as to when the people of Formosa were separated from the main stock.

Probably the latest migration was that which went eastward to North-West Polynesia. I imagine that this took place after those remaining in the Indian Archipelago had long been scattered through the various islands, and that these people went from one or more of the Eastern branches.

Now comes the question: are all the brown people at present found in the Indian Archipelago portions of one race? We know some-especially French writers-say, No. I cannot enter here into any arguments on this subject; but will simply say I believe they have all sprung from the same root stock, and that the isolation of some, and the greater contact of other's with civilising, and other influences have produced the differences now found in thern. Mr. Keane has called my attention to one most interesting fact bearing on this question, viz. : that the people found on the chain of small islands west of Sumatra, and who have been isolated from those on the larger islands, in some respects very closely resemble the Eastern Polynesians; in fact, they appear, to a great extent, to have retained what we may imagine the primitive condition of the whole family to have been at the time of the earliest migration.

For the branch of this family now in the Indian Archipelago, I propose to retain the name Malayan. Under this generic term will come the specific names Malay, Javanese, \&c. .

* See on this point, "Ethnology of Polynesia," "Journ. Anthrop. Inst.", Feb. 1879 ; pp. 261-74. 
For the two Eastern branches of the Malayo-Polynesians, I have to propose entirely new names. That in Eastern Polynesia and New Zealand I wish to call Savaiori. This word is a compound formed from the names of three representative peoples of that race; $S a$ from Samoa, wai from Hawai i (or I might say from the traditional Hawai'i or Hawaiki, which they say was the home of their race before their migrations), and ori from Maori. I know the principle of compounding names in this way has not met with much favour in this country. But Mr. Keane has pointed out to me one precedent. The word Horsoks, a collective name for the people of North Tibet, is compounded from Horpa and Sokpa.

Sawaiori may not sound particularly euphonious to those who hear it for the first time, but I think it will pass muster on this ground when we get accustomed to it.

I propose this name because these people have at present no name by which they, as a whole, are known to themselves, and because we have no good name for them. I know a proposal has already been made before this Institute to give a name to them, and something must be said in this connection on that proposal. In a paper which contains many other statements I should not like to endorse, Mr. Rankin says these people have "one family name by which they call themselves." And he explains that "as the dialects vary, as one group use the $r$, which another cannot pronounce, one the aspirate, another none, so the name of their race varies in different islands, but is always the same root. That name is Mahori in most southern groups, Mahoi in some, Maori in others. The first form Mahori would be recognised by the great majority as their own name, as distinctive from any Papuans or other foreigners."

If Mr. Rankin were correct in making that very positive statement, plainly Mahori would be the proper name for us to apply to all these people. But such is not the case. The word, as he gives it, does not occur at all in the languages of these people. In the Tahitian it has an aspirate before the final $i$ and becomes maohi; but nowhere has the second syllable an aspirate. The objection, however, to the word is, that in the languages where it occurs it is simply an adjective, which means true, real, and which has thus come to mean indigenous in contradistinction to that which is strange and foreign. In Tahiti, taata maoki means men of the soil; but the word may be used with other substantives to indicate native trees, native animals, or anything else which is indigenous. Even in the language of New Zealand the word is an adjective :- wai maori is true water: i.e., fresh water, to distinguish it from salt or sea water. In the same way tangata maori is a true man-a native. Manri as a 
substantive is not found in the New Zealand dictionary ; and I doubt whether its use as a substantive for the Maori people is a purely native use of the word at all. In Samoa tangata maoni (or rather tangata fa'amaoni, which alone would be good Samoan) would mean a true, honest, or correct man and never a native, unless it were used in such a sentence as $O$ le tangata fa'amaonio le nu' $u$, a true man of the place. From this you will see Mr. Rankin's proposed name has no claim whatever to the place he would give it.

For the people in North-West Polynesia hitherto known as Micronesians I also have a new name to propose, viz.: TÁraPON. This is from Tárawa in the Gilbert group; and Ponape in the Caroline, or Ebon in the Marshall Archipelagoes. The $b$ and $p$ being interchanged, the latter part of the word will represent both the Caroline and the Marshall Islands. Ebon and Ponape are the two islands in those archipelagoes about which we know most, and they may be considered fairly representative. I take the first element of the compound from Tárawa rather than any other atoll of the Gilbert Group, for the following reason. When Mr. Horatio Hale prepared his great work on the Ethnography and Philology of the United States Exploring Expedition, he adopted the word Tárawa for the Gilbert Island language. This is the name of one atoll only, the natives having no general name for the group. He has given a short grammar and vocabulary of this 'Tárawa language which philologists who have seen his book may remember. I think his name is therefore entitled to consideration; and in making this wider generalisation I take the first part of the name he adopted.

The people of Madagascar and Formosa of course need no new names. Malagasy and Formosan may be kept for them.

I have not assigned any special place to the Motu and other people of Eastern New Guinea, for the simple reason that their relationship with the other people has not yet been ascertained. There is little doubt but they are more or less mixed. We may, when we know more about them, have to call them subMalayan, or sub-Sawaiori ; just as I think it will be convenient to call some of the mixed people in Fiji, the Loyalty Islands, New Hebrides, \&c, sub-Papuan, to indicate that they are not pure Papuans.

My general scheme is set forth in the plan on pages 361 and 362.

It may be convenient, in conclusion, to recapitulate the changes proposed in this paper:-

1. To use Polynesia as the only geographic term for all the intertropical islands of the Pacific, eastward of the Philippine Islands and New Guinea, and to cease using Melanesia and Micronesia. 
2. To employ the names Austral, Negrito, and Papuan for the three dark races.

3. If any general name be employed for these three races, to call them Negrito-Polynesians.

4. Uniformly to use the name Malayo-Polynesian for all the brown people in Madagascar, Formosa, the Indian Archipelago, North-Western and Eastern Polynesia and New Zealand.

5. To call those in the Indian Archipelago Malayan, those in North-West Polynesia Tárapon, and those in Eastern Polynesia and New Zealand Sawaiori.

6. Perhaps to distinguish those people who are considerably mixed by the terms sub-Papuan, sub-Sawaiori, \&c., \&c.

\section{Discussion.}

Mr. A. R. WALLACE was sorry the paper had not been read some months earlier, as it might have somewhat affected the nomenclature he had adopted in a work on the geography of Australasia now passing through the press. He thought Mr. Whitmee's proposed alterations far too large and radical to have much chance of being adopted. Names already in use, and with a definite meaning, should not be changed without very weighty reasons. He thought "Melanesian" a good word, and generally understood. He, like Mr. Keane, objected entirely to the term Malayo-Polynesian as being wrong and misleading from a physical point of view. It implied that the Malays and the brown Polynesians were close allies; whereas they were really very remote allies, and the Malays were certainly much more nearly related to the natives of Burmah or even of China. To use the word Malay at all in connection with the Polynesians was misleading, as it implied a theory which was almost certainly wrong. There would perhaps be no harm in using the term Indo-Pacific, as suggested by Mr. Keane for all the insular races, but otherwise no general term was needed. $\mathrm{He}$ thought that the general principle of priority in nomenclature should apply in anthropology as in natural history ; and therefore, if any new term was applied to the Polynesians, Mr. Rankin's word "Mahori" should have the preference. It is euphonious, it implies no theory, and on Mr. Whitmee's own admission it was applicable, as meaning "indigenous" among the Polynesians themselves. As regards the black woolly-haired races, Papuan was certainly a good term, because it meant frizzly-haired, but it had come to be somewhat restricted to the natives of New Guinea itself, and its immediately surrounding islands. If used as a general term, it might be modified into Papuanese, which might include all the tribes or races from Flores on the west to Fiji on the east, the old term Melanesian being restricted to the frizzly-haired natives of the Pacific, east of New Guinea. Micronesia also was a term generally understood, and very useful as defining the small islands to the north of New Guinea, and east of the Philippines. It was a useful

VOL. VIII. 
geographical term, and implied no theory as to the people inhabiting the islands, who were more or less of mixed races. He thought Papuanese (or Melanesian) if adopted as a general term for the Eastern frizzly-haired people as contrasted with the African or Western, should include the Negritos as a matter of convenience, and because Dr Beccari had stated that he had seen some people from the interior of New Guinea, who very closely resembled them. If it should turn out that there were intermediate tribes between Papuans and Negritos, notwithstanding their considerable cranial differences, we should find the convenience of having one term to include the whole, just as the general term Negro includes the whole of the woolly-haired races of Africa, among whom somewhat analogous differences occur.

Professor FLOWER, F.R.S., said that he never entered into any questions bearing upon the revision of existing nomenclatures without thinking of two fundamental principles laid down by two leaders of our branch of science. Professor Owen once wrote that " the sooner a term becomes an arbitrary sign the better."* Professor Huxley tells us that " it is better for science to accept a faulty name which has the merit of existence than to burden it with a faultless newly invented one." $\uparrow$. But as knowledge increases, new words must be introduced, and the meaning of old ones must be restricted and defined, and if the subject is approached with caution, judgment, and a due sense of responsibility, as appears to be the case in Mr. Whitmee's communication, science may be advanced by their revisions. As Mr. Whitmee has invited criticisms, he ventured to offer some, although most of the points raised required more careful consideration than could be given to them in one evening. With regard to the term "Inter-Oceanic," it did not seem to him any improvement upon the generally used and well understood " Oceanic." He also would scarcely like to supersede "Micronesia," at all events as a geographical term; for such an objection as that, there were small islands in other parts of the world, to which might be applied a vast number of other names commonly in use ; and ho was not sure that the people inhabiting this region were a sufficiently distinct race to require a special designation, as they appear rather to be hybrids formed of several other races. For the light brown people of the Central and Eastern Pacific, Mr. Whitmee's "Sawaiori," he had himself been content to use the old word Polynesian, restricting it for the future to this race. For the dark people with frizzly hair, inhabiting mainly the Western Pacific, he preferred the term Melanesian; although much was certainly to be said for the older word Papuan. He doubted whether any general term was required to include the Negritos of the Andaman Islands, and the Papuans and Melanesians; as no definition could be given of these groups, which would exclude the African negroes and even the bushmen. Except the dark colour and woolly hair, there were

* "Trans. Geological Soc.," 1857, p. 55.

$\uparrow$ "Critiques and Addresses," p. 153. 
scarcely any physical characteristics common to the natives of the Andamanese and the New Hebrides.

Mr. Whitmee : In reply to the remarks of Mr. Wallace, Mr. Keane and Professor Flower, I may say, I have retained Malayo-Polynesian out of respect for Baron W. v. Humboldt, and because it is in use; otherwise Indo-Pacific would doubtless be the better term. I am prepared to accept Melanesian, or any other name which may commend itself to ethnologists ; but I must except " Mahori," which I think I could never accept. The brown Polynesians (Sawaióri) I do not regard as a mixed race ; they are the purest of the whole family. Those in North-West Polynesia (Tárapon) are mixed, quite a hybrid people. The blacks cannot be put under one term if it is to imply any close connection. The Australians are very different from the others. Negrito-Polynesian, if used, would be simply a convenient geographical name for the blacks of this region. But I am not prepared strongly to press the adoption of that name.

The following communication, entitled " Ethnological Notes on the Motu, Koitapu, and Neighbouring Tribes of New Guinea," was contributed by the Rev. W. G. LAwES.

\section{Ethnological Notes on the Motu, KoItApu and KoIARI Tribes of New Guinea. By Rev. W. G. Lawes.}

THE following paper is intended to be a sequel to one by Dr. W. Y. Turner on the "Ethnology of the Motu" which was read before this Institute and published in the Journal for May 1878. The information contained in it has been gathered during three years' residence (from December 1874 to December 1877) at Port Moresby.

I would repeat the caution given by Dr. Turner in his paper in reference to the size of New Guinea and the necessity of specifying with exactness the district about which statements are made and information given. This caution is more important in reference to the people than to the country; the diversities of race and tribe are so numerous. An illustration of this may be found in the fact that twenty-five different languages are certainly spoken on the 300 miles of const extending from Yule Island to China Straits. Many of these are, of course, dialects, but they differ from each other as much as those spoken on the different islands of Polynesia.

Port Moresby is in lat. $9^{\circ} 30^{\prime} \mathrm{S}$. and long. $147^{\circ} 10^{\prime} \mathrm{E}$., it is the centre of the Motu district which extends 18 miles to the east, and 30 miles to the west.

My knowlege of the Motu tribe is the greatest, but as Dr Turner has treated of it so fully in his paper, I shall simply 